\title{
A BIOMIMETIC STUDY OF THE EXPLOSIVE DISCHARGE OF THE BOMBARDIER BEETLE
}

\author{
N. BEHESHTI \& A.C. MCINTOSH \\ Energy and Resources Research Institute, University of Leeds, Leeds, UK.
}

\begin{abstract}
A biomimetic study of the bombardier beetle's explosive discharge apparatus was undertaken using numerical (CFD) modelling, first, of the beetle's combustion chamber, and then of a scaled-up combustion chamber with a view to its application to devices such as gas turbine relighters. The new findings about the existence of a pressure release valve at the beetle's combustion chamber exit yield a clearer understanding of the physics of the beetle's mass ejection mechanism. The scaled-up chamber (about $1 \mathrm{~cm}$ in length) is modelled by considering the chamber to be filled with liquid hexane which then undergoes vapour explosion through a pressure release valve at the exit. The ejection of vaporised fuel at high exit velocities has a number of applications, including gas turbine igniters.
\end{abstract}

Keywords: biomimetics, bombardier beetle, gas turbine relight, plasma injector, vapour explosion.

\section{INTRODUCTION}

A unique mechanism involving the discharge of hot products has been discovered to operate in certain types of Carabidae (ground beetles). These insects (of the family/genus Carabidae Brachinus) are found in South America, Africa and Asia (with a recent report of a Brachinus crepitans even appearing in the UK [1]). The defence mechanism of the brachinus beetle-commonly known as the bombardier beetle (Fig. 1) -is most unusual in that an aqueous combustible mixture of hydroquinone and hydrogen peroxide is catalysed by catalase and peroxidase which then heats the solution to boiling point. Evaporation then occurs within a few milliseconds and the mixture is ejected at $100^{\circ} \mathrm{C}$ on predators using a variable angle outlet nozzle which can be directed for pinpoint accuracy. The nozzle is so versatile that it can even be aimed forwards over the back of the beetle [2].

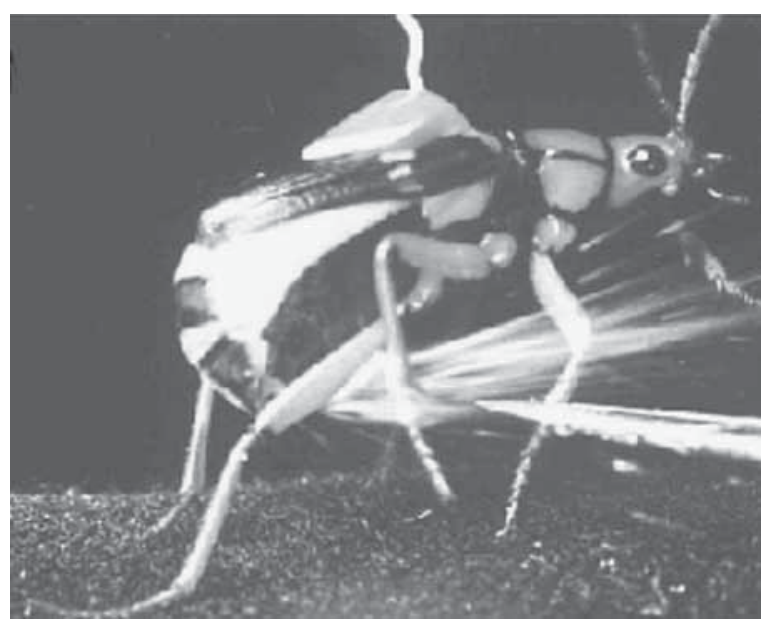

Figure 1: A bombardier beetle (brachina) ejecting its water-steam jet at $100^{\circ} \mathrm{C}$ forward from the tip of its abdomen (from left to right) (with permission from Prof. T. Eisner). 
The findings about this insect by Eisner and his group at Cornell University have inspired research into whether there are engineering advantages in the design of this discharge mechanism. Such advantages could be, for instance, a short mass ejection time and a long range of spray ejection (termed 'throw' in some applications). This is particularly pertinent to ignition devices such as those used in gas turbines [3], since the beetle has a very efficient mass ejection system. It has been found that the insect has the surprising ability to eject a hot discharge to around 200-300 times the length of its combustor (which for the beetle is about $1 \mathrm{~mm}$ ) [2, 4].

In this paper we describe the combustion and secretion mechanism of the beetle's discharge apparatus. In that the application to technological devices is the main motivation for this work, we then discuss the modelling of the water-steam explosion in a cylindrical chamber with a volume approximately equal to that of the beetle's combustion chamber. Specifically, we conduct a study of the phase change and two-phase flow in the combustion chamber of the beetle and investigate the effect of the exit nozzle diameter on its efficiency. Then a scaled-up chamber for application to gas turbine relight is simulated with a hydrocarbon fuel (hexane) instead of water. All the CFD simulations are performed using the CFX 5.7 code.

\section{THE CHEMISTRY AND THE SPECIFICATIONS OF THE BOMBARDIER BEETLE'S DISCHARGE APPARATUS}

The aqueous solution of reactants is stored in a reservoir, and is composed of hydroquinone $\left(\mathrm{C}_{6} \mathrm{H}_{6} \mathrm{O}_{2}\right)$ at a concentration of $25 \%$ and hydrogen peroxide at a concentration of $10 \%$ ([5] - concentrations assumed to be by mass, see [4]). Figure 2 shows a schematic representation of the beetle's discharge apparatus including the reservoir and the reaction chamber. When the reservoir is squeezed, the mixture of reactants is introduced into the reaction chamber through a valve, which is opened in the first part of the cycle. Once the reactants are present in the chamber, the enzyme catalysts (catalase and peroxidases) are introduced through the combustor walls. An extremely fast catalytic reaction

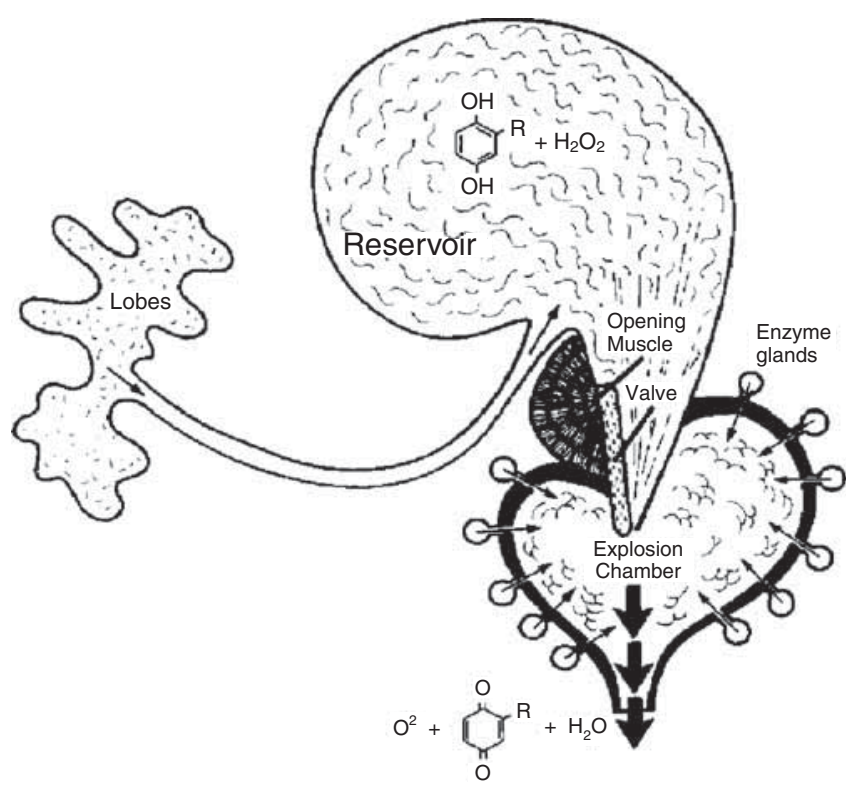

Figure 2: The bombardier beetle's discharge apparatus (with permission from Dr D. Rosevear). 
then takes place. While the hydrogen peroxide is decomposed with the help of catalase to water and free oxygen, the peroxidases play a role in the oxidation of hydroquinone. The reaction mechanism [4] can be described by the global chemical reaction:

$$
\mathrm{C}_{6} \mathrm{H}_{6} \mathrm{O}_{2}(\mathrm{aq})+\mathrm{H}_{2} \mathrm{O}_{2}(\mathrm{aq}) \rightarrow \mathrm{C}_{6} \mathrm{H}_{4} \mathrm{O}_{2}(\mathrm{aq})+2 \mathrm{H}_{2} \mathrm{O}(\mathrm{l})
$$

and it can also be described in three main decomposition steps:

$$
\begin{gathered}
\mathrm{C}_{6} \mathrm{H}_{6} \mathrm{O}_{2}(\mathrm{aq}) \rightarrow \mathrm{C}_{6} \mathrm{H}_{4} \mathrm{O}_{2}(\mathrm{aq})+\mathrm{H}_{2}(\mathrm{~g}) \\
\mathrm{H}_{2} \mathrm{O}_{2}(\mathrm{aq}) \rightarrow \mathrm{H}_{2} \mathrm{O}(\mathrm{l})+\frac{1}{2} \mathrm{O}_{2}(\mathrm{~g}) \\
\mathrm{H}_{2}(\mathrm{~g})+\frac{1}{2} \mathrm{O}_{2}(\mathrm{~g}) \rightarrow \mathrm{H}_{2} \mathrm{O}(\mathrm{l})
\end{gathered}
$$

Note that eqns (2)-(4) are not to be regarded as the breakdown of eqn (1). Rather they represent the salient reactions of a large number of reactions, and the important point is that the sum of the enthalpy changes of eqns (2)-(4) is equal to that of eqn (1). The enthalpy of reaction at $25^{\circ} \mathrm{C}$ for eqns (2)-(4) are $\Delta H_{2}=+177.2 \mathrm{~kJ} / \mathrm{mol}, \Delta H_{3}=-94.5 \mathrm{~kJ} / \mathrm{mol}$ and $\Delta H_{4}=-285.5 \mathrm{~kJ} / \mathrm{mol}$ respectively. So for the overall reaction [eqn (1)], one can consider the equivalent enthalpy as the addition of these three salient reactions [4], i.e. $\Delta H_{1}=-202.8 \mathrm{~kJ} / \mathrm{mol}$. The total heat released for $1 \mathrm{~kg}$ of solution is then $794.2 \mathrm{~kJ} / \mathrm{kg}_{\text {solution }}$.

However, the heating up stage is not modelled-we only consider the vapour explosion after the pressure release. The actual mechanism of the catalytic reaction used by the bombardier beetle involves increasing the kinetic rate of the chemical reaction of hydrogen peroxide and hydroquinone. This is done using the enzyme catalase, which decreases the activation energies in reactions eqns (2) and (3) at low temperatures and thereby allows the exothermic reaction eqn (4) to commence. However, by concentrating on the flash evaporation of water (due to the sudden pressure drop provided by the release of the exit valve) the essential elements of the physical behaviour of the system are retained.

Aneshansley et al. [4] measured the mass of the ejected liquid and gases and found that it varied from 0.1 to $0.5 \mathrm{mg}$ for a single discharge. While the reactant storage and delivery system is driven by muscle contraction, the reaction chamber is rigid. Eisner and colleagues [6] report spectrographic measurements of the discharge using seven beetles (45 discharges) and conclude that the average discharge duration was $11.9 \mathrm{~ms}$. The actual time elapsed was $2.6-24.1 \mathrm{~ms}$, with $2-12$ pulses per discharge recorded and thus a mean of 6.7 pulses per discharge. The frequency of the pulses is reported to range from 368 to $735 \mathrm{~Hz}$, with the mean value at $531 \mathrm{~Hz}$. The average velocity of the spray emerging from the tip of the beetle's abdomen was measured with a high-speed camera to be $11.63 \mathrm{~m} / \mathrm{s}$ (ranging from 3.25 to $19.5 \mathrm{~m} / \mathrm{s}$ ). The spray can reach as far as $20-30 \mathrm{~cm}$.

The beetle's discharge apparatus consists of two sets of reservoirs, reactors and exit nozzles. In Fig. 2 only one chamber is sketched. The outer view of the twin chambers and their exit nozzles from an electron micrograph is shown in Fig. 3.

\section{NUMERICAL MODELLING}

3.1 Numerical modelling of the beetle's combustion chamber: steam explosion (cavitation) model

By careful examination of the scanning electron micrographs provided by the Cornell group (see Fig. 3 as an example, where both reaction chambers are shown), it was concluded that the design of 
the exit nozzle system was crucial to the whole firing mechanism. The reaction chamber exhausts into these tubes, but it was noticed that at the entrance of the tube, the tube is not entirely rigid. The first section (near the reaction chamber) has a flexible membrane that acts as a very effective pressure relief valve, which obstructs the progress of the exhaust mixture to the downstream part of the exit nozzle. By examination of these detailed figures, it was proposed that the flexible lining opens only after a certain pressure is built behind it by the creation of boiling nuclei in the water. This observation then revealed that the major physical behaviour is in fact governed by a series of evaporative (steam) explosions. Since mechanical examination of the very small chamber and the valve system is not possible, especially to examine how the valve could affect the vapour explosion process, it was proposed that to verify the valve system, a computer simulation be used. The computational fluid dynamics (CFD) code chosen for this purpose was the commercial program CFX, since it is a proven and powerful simulation tool. The CFX package enables the complex governing equations of reactive fluid motion and phase change to be solved numerically. CFD methods are widely used for any fluidrelated engineering discipline and are recognised as a fast alternative to expensive experiments (for theories of CFD methods see e.g. [7] and [8]).

In order to capture the salient physical process of this extraordinary explosive mechanism, it was necessary for the CFD numerical simulations to include the two-phase boiling of water in the model. It had been suggested in earlier investigations [4] that the free oxygen generated by the action of catalase decomposing hydrogen peroxide to water [eqn (3) above] was the cause of the increase in pressure. This may contribute to the initial pressure rise. The $\mathrm{H}_{2} \mathrm{O}_{2}$ mass concentration in water can be as much as $25 \%$, but in this study it is assumed that heating combined with the pressure valve being closed up to a critical pressure above the atmospheric pressure is the main mechanism for the build-up of the ejection force. The addition of an exit valve shows that the firing is primarily due to water suddenly experiencing a pressure lower than its saturation pressure at higher temperature (slightly above $100^{\circ} \mathrm{C}$ )—effectively a pressure cooker effect. In every cycle, flash boiling shoots out a mixture of water and steam once a trigger pressure is reached.

Initially, the shape of the reaction chamber was thought to be significant, and the heart shape featured prominently in early CFD models [3]. However, the timescale of ejection resulting from instantaneous heating from the walls of such a system was far too long, whereas bringing in a steam explosion reduced the timescale of ejection to experimental values. Consequently, the shape for such

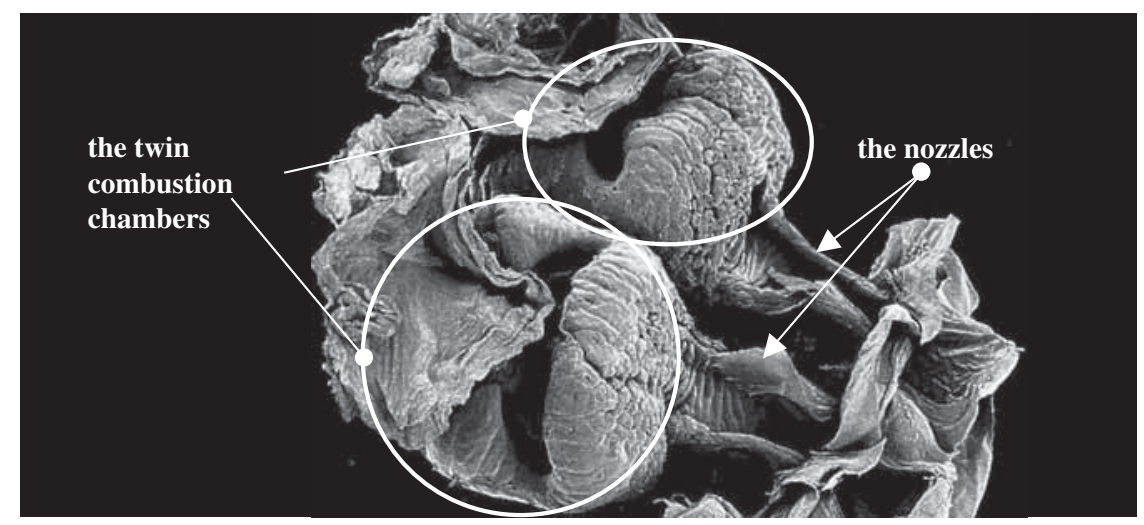

Figure 3: The twin box-glove shape combustion chambers and nozzles in the Stenaptinus insignis beetle from a dissection by Eisner [9]. 
calculations was not considered and a simple geometrical configuration was used. First, a very small cylindrical chamber $600 \mu \mathrm{m}$ in diameter and $300 \mu \mathrm{m}$ in length was chosen, having approximately the same volume as the beetle's chamber. To this was attached, in the numerical model, an exit nozzle $100 \mu \mathrm{m}$ in length and with seven different diameters of 60,100,150, 200, 300, 400 and $500 \mu \mathrm{m}$. For the initial conditions, the chamber was filled with pure liquid water at a saturation temperature $(378 \mathrm{~K})$ and with a pressure of $1.1 \mathrm{bar}$.

The initial condition for the nozzle outside the main chamber was to fill it with pure steam at the same temperature but at a lower pressure of 1.0 bar. This latter assumption was simply a useful numerical artefact for ease of calculation. There is very little essential difference to the real situation where the nozzle is filled with pure air, but the advantage in the numerical calculations is that this condition avoids the need to solve for three species. The numerical model then only solves the conservation equations for two species: liquid water and water vapour. At time $t=0$ it is assumed that the two parts (nozzle and chamber) are separated with an infinitely thin membrane (a simplified model for the pressure relief valve in the beetle) and that this is removed at time $t=0+$, allowing the two parts to then be in direct contact. As the pressure in the nozzle is lower than the saturation pressure for water at $T=378 \mathrm{~K}$, the water will then rapidly vaporise leading to a cavitation explosion.

In summary, the main assumptions in the physical model of the fluid dynamics are:

1. Full transient simulation.

2. Boiling is assumed to be an isothermal phenomenon occurring at the saturation temperature of water at $P=1.1$ bar $(T=378 \mathrm{~K})$.

3. An Eulerian (homogeneous) two-phase flow model is employed [10] with the Rayleigh-Plesset model for cavitation [11] as the phase change model. This model is available in CFX.

4. The flow is assumed to be laminar, since Reynolds numbers based on exit diameter are well below 2000.

5. Axial symmetry is assumed and only a 3D slice of the cylindrical chamber with an angle of $36^{\circ}$ is solved with symmetry boundary conditions on its sliced sides.

To resolve the rapid changes that occur by the cavitating phase change, a very small time step of $2.5 \mu \mathrm{s}$ was needed, and the calculations where terminated after a total time of $3 \mathrm{~ms}$ which was sufficient for wider nozzle diameters ( $200 \mu \mathrm{m}$ and above) to discharge all their dischargeable mass. The steam was assumed to be compressible (as an ideal gas), and due to the very small size of the chamber, a laminar flow assumption was made. Typical Reynolds numbers based on exit diameter were in the range 300-1000, which confirmed that laminar flow can readily be assumed. The Reynolds number $\operatorname{Re}$ is given by $\operatorname{Re}=U d / v$, where $U$ is the free stream velocity, $d$ is a reference length (in this case the diameter of the nozzle) and $v$ is the kinematic viscosity. The calculation in this case is complicated by being performed for a two-phase flow (with large variations in volume fractions of each phase in time and space). We have not included the details of the estimates with regard to Reynolds number in this paper.

\subsection{Numerical modelling of the scaled-up cylindrical combustion chamber}

In order to consider biomimetic applications of the combustion chamber of the beetle, a scaled-up chamber was also studied. For this investigation, a reaction chamber $20 \mathrm{~mm}$ in diameter and $10 \mathrm{~mm}$ in length was chosen and filled with liquid hexane at $10 \mathrm{bar}$ and at the saturation temperature for this pressure (about $170^{\circ} \mathrm{C}$ ). The exit nozzle was $7 \mathrm{~mm}$ long and with three different diameters of 3,5 and $7 \mathrm{~mm}$. For ease of calculation (avoiding the necessity to deal with more than two species-in a similar way to the calculation with steam), the nozzle was initially filled with gaseous hexane at 9 bar 
and with the same temperature as the chamber. The assumptions used were identical to those used in modelling the beetle's combustion chamber. As the Reynolds number based on the exit diameter is in the region of $10^{5}$ to $2 \times 10^{6}$, turbulent flow was assumed and the $k-\varepsilon$ turbulence model was used.

\section{RESULTS AND DISCUSSION}

\subsection{The beetle's combustion chamber}

Figure 4 shows the mass (water/steam) exit rate from the nozzle for the beetle's combustion chamber with different nozzle diameters. As one can see, the wider the nozzle, the higher the exit rate and the sooner the ejection process ends. However, as shown in Fig. 5, the maximum of the section-averaged exit velocities increases with decreasing nozzle diameters up to $200 \mu \mathrm{m}$ and then decreases with smaller diameters. For calculation of the section-averaged velocity, mass flow weighting is used.

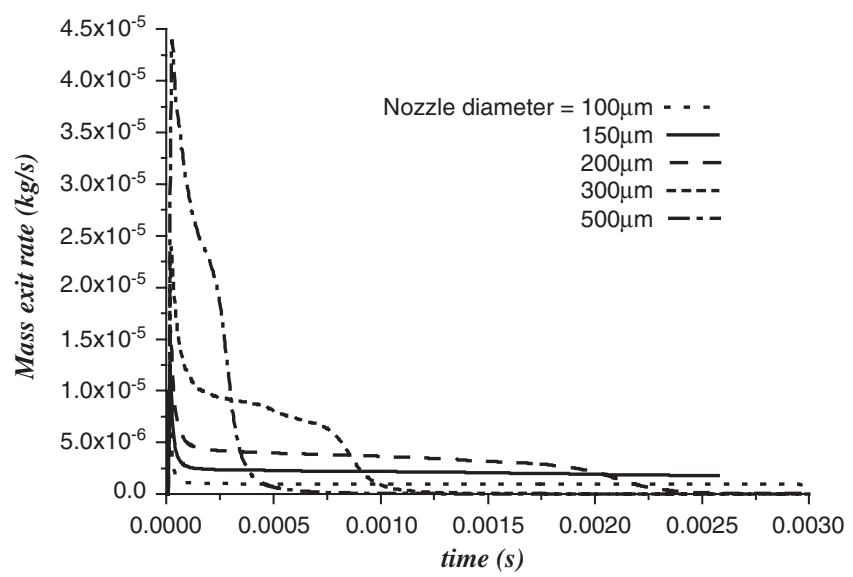

Figure 4: Exit mass flow rate for five different nozzle diameters for the beetle's combustion chamber.

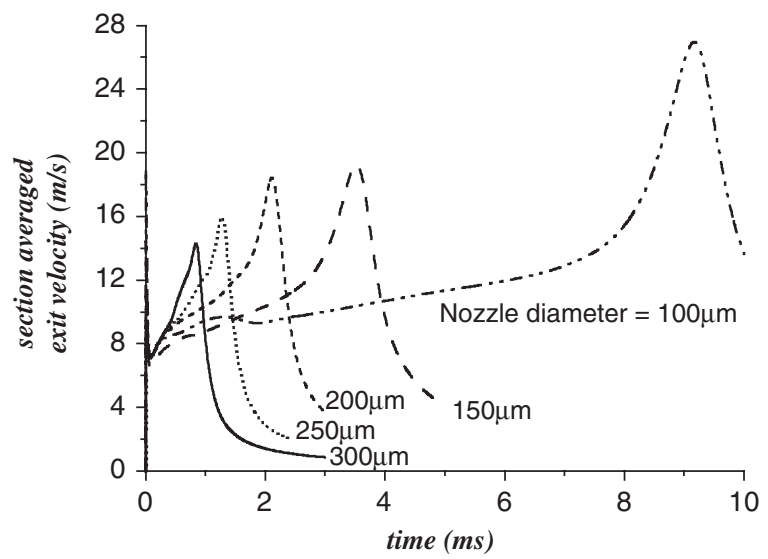

Figure 5: Section-averaged exit velocity for four different nozzle diameters for the beetle's combustion chamber. 
This is done as follows: at each numerical grid point on the exit section, the local mass flow exit rate is multiplied by local velocity and is integrated over the whole exit section. This is then divided by the integral of the exit mass flow rate over the exit section. This gives an indication of the average velocity responsible for the exit mass flow rate of the beetle's spray.

For the defence mechanism of the beetle (and also for the gas turbine igniter application) it is important to deliver the charge at the maximum possible velocity. As the velocity increases, the longer will be the effective range for the jet and it will also reach the predator earlier. Consequently, there is an optimum size for the nozzle diameter. This is found to be approximately $200 \mu \mathrm{m}$ in these simulations, since the section-averaged velocity is higher than that for larger nozzles and the ejection is completed in just $2 \mathrm{~ms}$. Although, the $100 \mu \mathrm{m}$ nozzle shows a much higher velocity, it takes much longer than the other nozzles to provide it - too late for the beetle to survive most predators. Therefore, the only rival for the $200 \mu \mathrm{m}$ nozzle is the $150 \mu \mathrm{m}$ nozzle which gives same velocity as the $200 \mu \mathrm{m}$ nozzle, but slightly later. Measurements of the nozzle diameter from the scanned electron microscopic slides taken in Cornell by Eisner [9] (e.g. Fig. 3) gives very close agreement to the $200 \mu \mathrm{m}$ nozzle $( \pm 10 \%)$. This shows that the nozzle diameter in the beetle device is in fact close to an optimum design and in principle can be duplicated for engineering applications. Work on smaller sizes of the overall beetle combustion chamber has revealed that this optimum size of exit diameter for the chamber scales is also observed in smaller beetles. It should also be noted that the average and the maximum velocities for this diameter (12 and $18.5 \mathrm{~m} / \mathrm{s}$, respectively) and the ejection timescale $(2 \mathrm{~ms})$ are very close to the experimentally measured values for the beetle spray $(11.63 \mathrm{~m} / \mathrm{s}, 19.5 \mathrm{~m} / \mathrm{s}$ and $2-3 \mathrm{~ms}$, respectively). This confirmed the proposal that the pressure release valve system is a significant component of the behaviour of the beetle's ejection system.

\subsection{Scaled-up chamber}

Simulation of the vapour explosion in the scaled-up chamber, filled with pure hexane as the vaporising liquid, gives similar results to those observed for the beetle's chamber filled with water (see Fig. 6). However, there are some apparent differences.

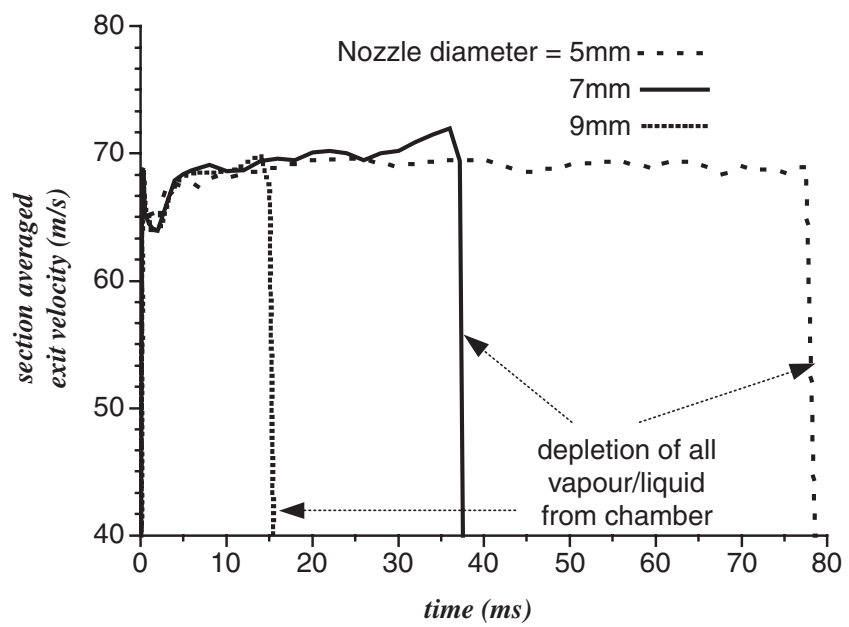

Figure 6: Maximum section exit velocities for three different nozzle diameters using the scaled-up chamber filled with hexane. 
The most significant difference is that since the resulting Reynolds number is of the order of $10^{6}$, the flow is highly turbulent, as this is an internal flow and the critical Reynolds number is approximately 2500. The critical Reynolds number is the value above which a laminar flow changes to a turbulent flow. This is in the region of 2500 for internal flows, and approximately $5 \times 10^{5}$ for external flows [12]. Therefore, in this case, a model of turbulence is necessary and here we used the well-known first order model known as the ' $k-\varepsilon$ model' [13] to capture the turbulence effects. Also, since the chamber is much larger, and the timescale of cavitation phase change is roughly the same, the time required for vaporising all of the liquid is longer. A further difference is that the larger chamber allows the back and forth passage of a significant number of pressure waves which encourage the dispersion of boiling nuclei and some unevenness in the flow.

In present aircraft gas turbines the igniters work by electrically charged air/water vapour being shot into the engine's combustion chamber by the sudden generation of plasma of radicals which chemically restart the ignition of the fuel-air mixture. Due to limitations of the throw distance of such an ejection and the early recombination of the radicals, new methods of efficient mass ejection have been considered. Figure 6 illustrates that such efficiency is achievable with a hydrocarbon fuel (hexane). This fuel has been used because it has a similar boiling temperature to kerosene (aviation fuel). For the scaled-up chamber the initial pressure is 10 bar and the ambient pressure is 9 bar (the typical gas turbine operation pressure). Figure 6 indicates that the $7 \mathrm{~mm}$ diameter nozzle gives the largest velocity within a $100 \mathrm{~ms}$ delivery time.

The development of a fast mass ejection device has a particular application to gas turbine igniters where it is important to eject vaporised fuel into the part of the combustion chamber where the combustion has ceased.

\section{CONCLUSIONS}

A numerical model of the very small bombardier beetle combustion chamber (approximately $1 \mathrm{~mm}$ long) has demonstrated that the significant physical behaviour behind the mass ejection efficiency is a cavitation explosion from hot water under pressure. Sudden decompression kicks the boiling liquid out of its moveable turret rear nozzle.

A scaled-up version of the same type of combustion chamber ( $20 \mathrm{~mm}$ long) has been numerically modelled using the same vapour explosion technique and a good mass ejection efficiency has been demonstrated. The advantage this could give gas turbine igniters is a promising biomimetic application.

\section{ACKNOWLEDGEMENTS}

The financial support of EPSRC (Engineering and Physical Sciences Research Council) UK is gratefully acknowledged.

\section{REFERENCES}

[1] BBC News, 11 November 2003, 'Windy' beetle found at reserve-Brachinus crepitans http://news.bbc.co.uk/1/hi/wales/south_east/3258563.stm, last accessed Monday, 21 March 2005.

[2] Aneshansley, D.J. \& Eisner, T., Spray aiming in the bombardier beetle: photographic evidence, Proceedings of the National Academy of Sciences USA, 96, pp. 9705-9709, 1999.

[3] Forman, M. \& McIntosh, A.C., The efficiency of the explosive discharge of the bombardier beetle with possible biomimetic applications. Design \& Nature II, eds. M.W. Collins \& C.A. Brebbia, WIT Press: Southampton and Boston, pp. 227-236, 2004. 
[4] Aneshansley, D.J., Eisner, T., Widom, M. \& Widom, B., Biochemistry at $100^{\circ} \mathrm{C}$ : explosive secretory discharge of bombardier beetles (brachinus). Science, 165, pp. 61-63, 1969.

[5] Schildknecht, H. \& Holoubek, K., Angewandte Chemie, 73, pp. 1-7, 1961.

[6] Dean, J., Aneshansley, D.J., Edgerton, H. \& Eisner, T., Defensive spray of the bombardier beetle: a biological pulse jet. Science, 248, pp. 1219-1221, 1990.

[7] Tannehill, J.C., Anderson, D.A. \& Pletcher, R.H., Computational Fluid Mechanics and Heat Transfer, 2nd edn, Taylor \& Francis: Philadelphia, 1997.

[8] Versteeg, H.K. \& Malalasekera, W., An Introduction to Computational Fluid Dynamics-The Finite Volume Method, Addison Wesley (Longman): Harlow, 1995.

[9] Eisner, T., Private communication, 2002.

[10] Drew, D.A., Mathematical modelling of two-phase flow, Annual Review of Fluid Mechanics, pp. 261-291, 1983.

[11] Young, F.R., Cavitation, McGraw-Hill Book Company (UK) Limited: London, 1989.

[12] Fox, R.W., McDonald, A.T. \& Pritchard, P.J, Introduction to Fluid Mechanics, 6th edn, Wiley: New York and Chichester, 2005.

[13] Launder, B.E. \& Spalding, D.B., The numerical computation of turbulent flows. Computer Methods in Applied Mechanics and Engineering, 3, pp. 269-289, 1974. 